\title{
S-1
}

Supporting information for the paper

\section{Real-Time Image Acquisition for Absorbance Detection and Quantification in Thin-Layer Chromatography}

Michael Lancaster ${ }^{\mathrm{a}}$, David M. Goodall ${ }^{\mathrm{a}^{*}}$, Edmund T. Bergström ${ }^{\mathrm{a}}$, Sean McCrossen ${ }^{\mathrm{b}}$, Peter Myers $^{\mathrm{a}}$

a) Department of Chemistry, University of York, York YO10 5DD, UK.

b) GlaxoSmithKline, Old Powder Mills, Tonbridge TN11 9AN, UK.

The supporting information is a PowerPoint Show document with the file name TLC.pps. The show contains three slides, showing the data collected during a TLC run of $10 \mathrm{ng}$ Sudan II processed as described for Figure 4 A, B and C in the main manuscript. Each slide presents the data for the whole TLC development in an animated fashion running at approximately 10 times actual speed. 